Brief communications:

\title{
Lysosomes of Cancerous and Normal cells in Response to Low-energy/low-dose Medical Diagnostic X-rays \\ Montree Tungjai ${ }^{1}$, Nuttakan Tubthaing ${ }^{2}$, Suchart Kothan3
}

\begin{abstract}
:
Background: Low-energy/low-dose ionizing radiation is increasingly being used in medical diagnosis, yet the effects of low-energy/low-dose medical diagnostic X-rays on biological systems remains a mystery. Thus, the aim of this present study is to determine the characteristics of lysosomes of cancerous and normal cells in response to low-energy/low-dose medical diagnostic X-rays. Methods and materials: Three cell lines composed of peripheral blood mononuclear cells (PBMCs), adriamycin-sensitive erythroleukemia cells (K562), and adriamycin-resistant erythroleukemia cells (K562/adr), were all exposed to low-energy/low-dose medical diagnostic $\mathrm{X}$-rays that operated at 50,70 , and $100 \mathrm{kV}$, and $100 \mathrm{mAs}$ for obtaining radiation doses at 0.03 , 0.07 , and $0.10 \mathrm{mGy}$, respectively. Accumulation of acridine orange in the lysosomes of each cell line was determined using flow cytometry completed at 4 and 6 hours-post irradiation. Results: The data showed an increase in fluorescence intensity of acridine orange in three irradiated cells line at 4 hours post-irradiation, but this intensity did not change at 6 hours post-irradiation when compared to that of corresponding non-irradiated cells. Conclusion: This finding suggests that changes in lysosomes might be a response to low-energy/low-dose medical diagnostic X-rays.
\end{abstract}

Keywords: Lysosome; Medical diagnostic X-ray; Radiation

Bangladesh Journal of Medical Science Vol. 18 No. 04 October'19. Page : 830-834 DOI: https://doi.org/10.3329/bjms.v18i4.42915

\section{Introduction}

It is well known that high doses of ionizing radiation can induce harmful health effects. However, a low dose of ionizing radiation is still not fully recognized as a potential health risk. There are several studies that have indicated that the effects of low dose and high dose ionizing radiation is dissimilar with regard to biological responses. Regardless of this evidence, the health risks of exposure to low dose ionizing radiation are still being examined, as low dose ionizing radiation is increasingly being used in medical diagnosis ${ }^{1}$. Ionizing radiation not only induces nuclear DNA damage, but intracellular organelles such as lysosomes, can also be affected ${ }^{2}$. Lysosomes are acidic intracellular organelles that contain several enzymes that can break down many kinds of intracellular molecules such as DNA, lipids, and proteins. It also acts as a waste elimination system for the cell by digesting unwanted molecules from extracellular and intracellular compartments in the cytoplasm. Extracellular molecules are up taken through a process of endocytosis, while intracellular molecules are digested through autophagy ${ }^{3}$. Some evidence suggests that ionizing radiation induces authophagy in several types cancer cells such as bladder $^{4}$ and, colorectal cancer cells ${ }^{5}$ However, this evidence was demonstrated only by exposure to high doses of ionizing radiation to induce these damaging effects. Thus, the aim of present study was to determine the characteristics of lysosomes in both cancerous and normal cells in response to lowenergy/low-dose medical diagnostic X-rays.

1. Montree Tungjai

2. Nuttakan Tubthaing

3. Suchart Kothan

Department of Radiologic Technology, Faculty of Associated Medical Sciences, Chiang Mai University, 110 Intawaroroj Rd., Sripoom, Chiang Mai, 50200, Thailand.

Correspondence to: Montree Tungjai, Department of Radiologic Technology, Faculty of Associated Medical Sciences, Chiang Mai University, 110 Intawaroroj Rd., Sripoom, Chiang Mai, 50200, Thailand. E-mail: mtungjai@gmail.com 


\section{Materials and Methods}

\section{Cell culture}

This present study used peripheral blood mononuclear cells as a model for normal cells. Cells were isolated and cultured following procedures listed in our previous reports ${ }^{6}$. Peripheral blood mononuclear cells were isolated using ficoll hypaque solution (Lymphoprep $^{\mathrm{TM}}$, Oslo, Norway). The number of viable cells was determined by a trypan blue exclusion assay. The number of cells was determined by haemocytometer. Freshly isolated peripheral blood mononuclear cells were cultured to obtain a total number equaling $10^{6}$ cells $/ \mathrm{mL}$ in a tissue-culture flask containing RPMI 1640 medium, supplemented with $10 \%$ heat-inactivated fetal bovine serum and $1 \%$ penicillin/streptomycin. Cells were incubated at $37{ }^{\circ} \mathrm{C}$ in a humidified $5 \% \mathrm{CO}_{2}$ atmosphere.

Cancerous cells line was cultured following the procedure listed in our previous report ${ }^{7}$. Adriamycinsensitive erythroleukemia cells line (K562) and adriamycin-resistant erythroleukemia cells line (K562/adr, overexpressing P-gp), were also cultured in a tissue-culture flask containing RPMI 1640 medium, supplemented with $10 \%$ heat-inactivated fetal bovine serum and $1 \%$ penicillin/streptomycin. As was the case for normal cells, cancerous cells were incubated at $37{ }^{\circ} \mathrm{C}$ in a humidified $5 \% \mathrm{CO}_{2}$ atmosphere. Both cancer cells lines cultures initiated a total of $10^{5}$ cells $/ \mathrm{mL}$ before being exponentially proliferating to a total of $8-10 \times 10^{5}$ cells $/ \mathrm{mL}$ over 3 days. For the experiment, cultures were initiated at $5 \times 10^{5}$ cells $/ \mathrm{mL}$ to obtain cells in exponential growth phase to a total of about $8-10 \times 10^{5}$ cells $/ \mathrm{mL}$ over 24 hours. The total number of viable cells was determined by a trypan blue exclusion assay. The total number of cells was determined by haemocytometer.

\section{Irradiation system}

An irradiation system was designed based on a procedure indicated in one of our previous reports ${ }^{6}$. Tissue culture flasks were placed in the center of an $\mathrm{X}$-ray beam at a distance of $100 \mathrm{~cm}$ from the X-ray tube. A medical diagnostic X-ray machine (Quantum medical imaging, Quest HF series, Caresteam, NY, USA) operating at 50,70 , and $100 \mathrm{kV}$, and $100 \mathrm{mAs}$ was used. Table 1 shows the parameters obtained by this medical X-ray machine. Energy spectra of $\mathrm{X}$-ray from medical diagnostic X-ray machine that operated at 50,70 , and $100 \mathrm{kV}$ was also shown in one of our previous studies 8
Table 1 The parameters obtained by the medical $X$-ray machine used in this study.

\begin{tabular}{|c|c|c|c|c|c|c|}
\hline \multicolumn{2}{|c|}{ Setting } & \multirow{2}{*}{$\begin{array}{c}\text { Measurement } \\
\text { Exposure, } \\
\text { nC }\end{array}$} & \multicolumn{2}{|c|}{ Calculation } & \multirow{2}{*}{$\begin{array}{l}\text { HVL, } \\
\text { mmAl }\end{array}$} & \multirow{2}{*}{$\begin{array}{l}\text { Target } \\
\text { /filter }\end{array}$} \\
\hline $\mathrm{kV}$ & $\mathrm{mAs}$ & & $\begin{array}{c}\text { Exposure, } \\
\mathrm{R}\end{array}$ & $\begin{array}{c}\text { Total dose, } \\
\text { mGy }\end{array}$ & & \\
\hline 50 & 100 & 0.03 & 0.0036 & 0.03 & 3.1 & W/Al \\
\hline 70 & 100 & 0.06 & 0.0073 & 0.07 & 3.1 & W/Al \\
\hline 100 & 100 & 0.09 & 0.0109 & 0.10 & 3.1 & W/Al \\
\hline
\end{tabular}

$\mathrm{kV}=$ kilovoltage, $\mathrm{nC}=$ nanocoulomb $\mathrm{R}=$ roentgen, $\mathrm{W}=$ tungsten, $\mathrm{Al}=$ aluminum

\section{Accumulation of acridine orange in lysosomes}

The accumulation of acridine orange in various intracellular organelles such as in the cytoplasm, nucleus, and lysosome expressed an emission spectrum of light that can be determined by flow cytometer based on the following: 1) Acridine orange in cytoplasm emits bright green fluorescence, 2) Acridine orange in the nucleus emits dim red fluorescence, and 3) Acridine orange in lysosomes emits bright red fluorescence?. Figure 1 shows the typical fluorescence intensity of acridine orange in cells taken from a flow cytometer. In the presence of $3 \mu \mathrm{M}$ monensin, bright red fluorescence intensity decreased (Figure 1A), whereas bright green fluorescence intensity increased (Figure 1B). It is suggested that acridine orange is released from the lysosomes into the cytoplasm.

The authors determined the accumulation of acridine orange in lysosomes occurring at 0,4 , and 6 hours post-irradiation using a flow cytometer. For the assays, $10^{6}$ cells were suspended in $1 \mathrm{~mL}$ phosphate buffer saline at a $\mathrm{pH}$ of 7.25 in the presence of $1 \mu \mathrm{M}$ acridine orange for 30 minutes prior to determination of florescence intensity with flow cytometer (Coulter Epics XL-MCL).

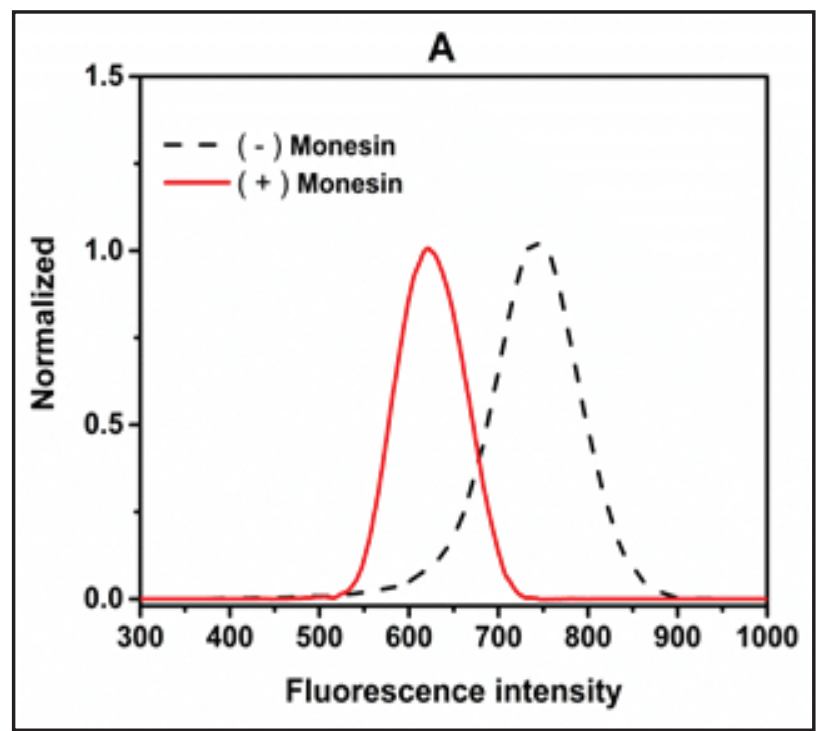




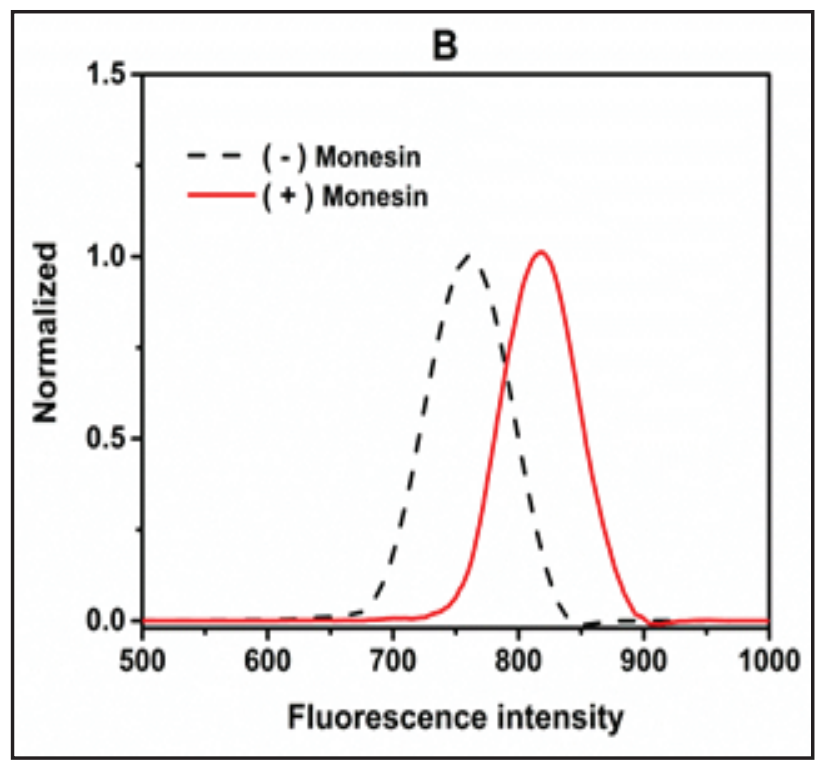

Figure 1. Typical histograms of fluorescence intensity of acridine orange accumulated in lysosomes (A) and cytoplasm (B). Cells were incubated with $1 \mu \mathrm{M}$ acridine orange for 30 minutes. The fluorescence intensity was recorded by flow cytometer without or after immediately adding $3 \mu \mathrm{M}$ of monensin. The total number of cells in each histogram was 10,000 cells.

\section{Results and Discussion}

Previously, we indicated that low energy/low-doses of medical diagnostic X-rays did not significantly change various biological end points such as hemolysis, osmotic fragility, fluorescence anisotropy, mitochondrial membrane potential, the cell cycle, and the number of apoptotic cells of irradiated cells as compared to corresponding non-irradiated groups at each time end point ${ }^{8-10}$.

Figure 2 summarizes the results as histograms of the accumulation of acridine orange in lysosomes. The number of cells in each histogram was 10,000 cells. For the peripheral blood mononuclear cells, the histograms of accumulation of acridine orange in lysosome of cells were collected at 4 and 6 hours after an in vitro exposure to various low-energy/low-doses of medical diagnostic X-rays. This also included the results of corresponding non-irradiated control groups. This data shows and increase in fluorescence intensity for irradiated cells, relative to that of the corresponding non-irradiated cells at 4 hours postirradiation (Figure 2A - C). Fluorescence intensity shows no change in irradiated cells, as compared to the corresponding non-irradiated cells at 6 hours post-irradiation (Figure 2A - C). The histograms for adriamycin-sensitive erythroleukemia cells (K562) and adriamycin-resistant erythroleukemia cells (K562/adr, overexpressing P-gp), show the accumulation of acridine orange in lysosomes of cells collected at 4 and 6 hours after an in vitro exposure to various low-energy/low-dose of medical diagnostic X-rays, and that of the corresponding non-irradiated groups. This data shows that an increased fluorescence intensity of irradiated cells had taken place, in relation to the corresponding nonirradiated cells at 4 hours post-irradiation (Figure2 D - I). Fluorescence intensity showed no change in irradiated cells, as compared to the corresponding non-irradiated cells at 6 hours post-irradiation time (Figure2 D - I).

The present results suggest that lysosomes had responded to radiation within 4 hours postirradiation time and then regulated to a resting stage at 6 hours post-irradiation. Acridine orange, an intrinsic fluorescent probe, is often used to determine the luminal $\mathrm{pH}$ of intracellular acidic compartments, like lysosomes. The accumulation of acridine orange in the lysosome depends on the $\mathrm{pH}$ gradient across the lysosome, so a collapse of the $\mathrm{pH}$ gradient results in acridine orange being released from the lysosome ${ }^{11}$. This present result shows an increase in the accumulation of acridine orange in lysosomes occurring at 4 hours post-irradiation. It could be possible that the lysosomes had responded to radiation by increments of $\mathrm{pH}$ gradient. However, since this was a preliminary study, the effects of low-energy/low-dose medical diagnostic X-ray on lysosomes needs to be better understood based on further research.

\section{Conclusions}

These findings suggest that the lysosomes may have responded to low-energy/low-dose medical diagnostic X-rays.

\section{Acknowledgments}

The authors would like to thank The Department of Radiologic Technology, Faculty of Associated Medical Sciences, Chiang Mai University, Chiang Mai, Thailand for their support and use of their facilities.

Ethical clearance: Blood sample collections were performed under the approved guidelines set by The Institutional Committees on Research Involving Human Subjects, and approval for testing was obtained by The Faculty of Associated Medical Sciences, Chiang Mai University.

Conflict of interest: The authors declared no potential conflicts of interest 


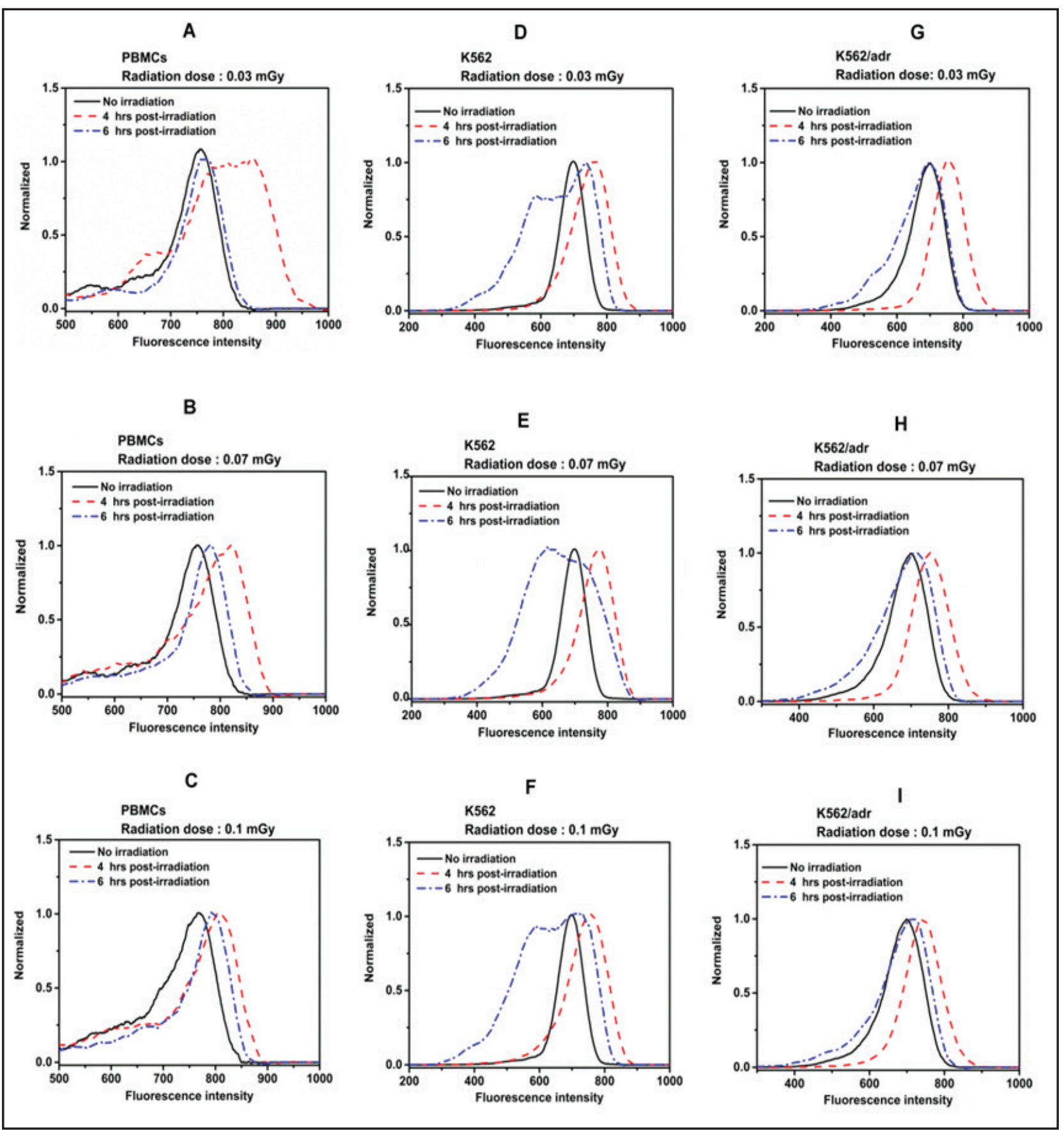

Figure 2. Histograms of accumulation of acridine orange in lysosomes of peripheral blood mononuclear cells (PBMCs), adriamycin-sensitive erythroleukemia cells (K562), and adriamycin-resistant erythroleukemia cells (K562/adr, overexpressing P-gp) after irradiation. The number of cells in each histogram was 10,000 cells.

\section{Individual Contribution of the Authors:}

Conceptual work: Montree Tungjai, Nuttakan Tubthaing, Suchart Kothan

Data collection: Montree Tungjai, Nuttakan Tubthaing, Suchart Kothan

Manuscript writing: Montree Tungjai, Nuttakan Tubthaing, Suchart Kothan

Editing of final manuscript: Montree Tungjai, Nuttakan Tubthaing, Suchart Kothan 


\section{References:}

1. Rithidech KN. Health benefits of exposure to lowdose radiation. Health Phys 2016; 110(3): 293-295. https://doi.org/10.1097/HP.0000000000000430

2. Persson HL, Kurz T, Eaton JW and Brunk UT. Radiation-induced cell death: importance of lysosomal destabilization. Biochem $J$ 2005; 389:877-884. https://doi.org/10.1042/BJ20050271

3. $\mathrm{Xu} \mathrm{H}$ and Ren D. Lysosomal Physiology. Annu Rev Physiol 2015; 77:57-80. https://doi.org/10.1146/annurev-physiol-021014-071649

4. Wang F, Tang J, Li P, Si S, Yu H, Yang X, Tao J, Lv Q, Gu M, Yang $\mathrm{H}$ and Wang Z. Chloroquine enhances the radiosensitivity of bladder cancer cells by inhibiting autophagy and activating apoptosis. Cell Physiol Biochem 2018; 45:54-66. https://doi.org/10.1159/000486222

5. Hu JL, He GY, Lan XL, Zeng ZC, Guan J, Ding Y, Qian XL, Liao WT, Ding YQ and Liang L. Inhibition of ATG12mediatedautophagybymiR-214enhancesradiosensitivity in colorectal cancer. Oncogenesis 2018; 7:16. https://doi.org/10.1038/s41389-018-0028-8

6. Tungjai M, Phathakanon N, and Rithidech KN. Effects of medical diagnostic low-dose x ray on human lymphocytes: mitochondrial membrane potential, apoptosis and cell cycle. Health Phys 2017; 112(5):458-464. https://doi.org/10.1097/HP.0000000000000647
7. Keeddee J, Rattanaworasin N, and Tungjai M.The effect of methoxyflavone on P-glycoprotein-mediated transport and intracellular reactive oxygen species in cancer cells. Biosci Biotechnol Res Asia 2011; 80:11-18. https://doi.org/10.13005/bbra/818

8. Tungjai M, Phathakanon N, Ketnuam P, and Kothan S. Determination of hemolysis, osmotic fragility and fluorescence anisotropy on irradiated red blood cells as a function of $\mathrm{kV}$ of medical diagnostic x-rays. Int J Radiat Res 2018; 16(1):123-127.

9. Dechsupa N and Mankhetkorn S. P-Glycoproteinmediated efflux and drug sequestration in lysosomes confer advantages of K562 multidrug resistance sublines to survive prolonged exposure to cytotoxic agents. Am J Appl Sci 2009; 6(9):1637-1646. https://doi.org/10.3844/ajassp.2009.1637.1646

10. Ahmad, W., Zulkifle, M., Hamiduddin, -, Afreen, S., \& Rahman, O. (2019). Explanation and elucidation of cancer in reference to Greco-Arabic literature. Bangladesh Journal of Medical Science 2019; 18(2):184-189. https://doi.org/10.3329/bjms.v18i2.40683

11. Dell'Antone P. and Piergallini L. The antineoplastic drug lonidamine interferes with the acidification mechanism of cell organelles. Biochim Biophys Acta 1997; 135 